\title{
Maternal deaths in developing countries: A preventable tragedy
}

\author{
Gunnar Kvåle ${ }^{1}$, Bjørg Evjen Olsen ${ }^{1}$, Sven Gudmund Hinderaker ${ }^{1}$, \\ Magnar Ulstein ${ }^{2}$ and Per Bergsjø $\varnothing^{2,3}$ \\ 1) Centre for International Health, University of Bergen, Bergen \\ 2) Department of Obstetrics and Gynecology, University of Bergen, Bergen \\ 3) Norwegian Institute of Public Health, Division of Epidemiology, Oslo, Norway \\ Correspondence: Gunnar Kvåle, Centre for International Health, Armauer Hansen Building, University of Bergen, 5021 Bergen, Norway \\ Telephone: +4755974656 Telefax:+4755974979 e-mail.gunnar.kvale@cih.uib.no
}

\begin{abstract}
SUMMARY
The neglected tragedy of persistent high maternal mortality in the low-income countries is described. One of the millennium development goals states that the current number of maternal deaths of around 500,000 per year should be reduced by three quarters by 2015. Since the major causes and avenues for prevention are known, this may seem an achievable goal. It is concluded, however, that unless all stakeholders globally and within individual countries will demonstrate a real commitment to translate policy statements into actions, it is unlikely that the goal will be reached. A substantial increase in the resources for reproductive health care services is needed, and the human resource crises in the health care systems must be urgently addressed. Epidemiologists have an important role to play by designing randomized controlled trials for estimating the effect of different health care systems interventions aimed at reducing maternal mortality and other major health problems in low resource settings. The public health importance of such trials may be greater than the potential benefit of randomized trials for investigating effects of new vaccines and drugs. Within the field of perinatal epidemiology the disparity in public health importance of research conducted in the rich versus the poor world is glaring. Time is overdue for perinatal epidemiologists to turn their attention to the areas of the world where the maternal and perinatal health problems are overwhelming.
\end{abstract}

\section{INTRODUCTION}

Every year, around 500,000 women die from complications of pregnancy and childbirth, and more than $99 \%$ of these deaths occur in less developed regions (1). For each woman who dies of a pregnancy-related condition, it is estimated that $15-30$ women suffer from serious damage and that in sub-Saharan Africa alone, between 50,000 and 100,000 women each year develop fistulas in the birth canal that allow leakage of urine or faeces (2). As a consequence, many of them become social outcasts, rejected by their husbands and families.

Of all health statistics monitored, maternal mortality is the one showing the largest difference between developed and developing countries. Current estimates of maternal mortality ratios vary from more than 1000 per 100,000 live births in some the African countries, to around 500 in many countries in Asia, 200-400 in several countries in South America and less than 10 per 100,000 live births in some European countries (1). There are great variations within the different regions (Figure 1). In some areas of East Africa the lifetime risk of a maternal death reaches 1 in 11 in contrast to around 1 in 5000 in Sweden and Norway, representing an almost 500-fold difference.

The persistent high maternal mortality has for many years been a neglected tragedy, as pointed out by
Rosenfield and Maine already in 1985 (3). However, even today, 20 years after their article in the Lancet was published and after many years with high international awareness of the problem, little progress has been made. These deaths represent a larger tragedy than deaths from many other diseases since they are very painful and potentially preventable. The causal factors are known; most of them being related to lack of provision of appropriate health care.

The millennium development goal no. 5 states that by 2015 the maternal mortality ratio should be reduced by three quarters (1). In this paper we will point to some of the necessary preconditions for achieving this goal, by describing the main causes of maternal mortality, the tools necessary to prevent maternal deaths, and what could be done to make these tools available for a larger proportion of the pregnant women. Our focus will be on the situation in sub-Saharan African countries where maternal mortality ratios are still very high.

\section{MEDICAL CAUSES OF MATERNAL MORTALITY}

Medical conditions leading to a maternal death are often classified as direct and indirect causes, the direct causes until recently estimated to account for approximately $80 \%$ and the indirect causes for approximately $20 \%$ (4). The estimates of this distribution seem to be 


\section{Figure 1 Maternal mortality ratio per 100,000 live births for selected countries (source: World Health Report 2005 (1))}

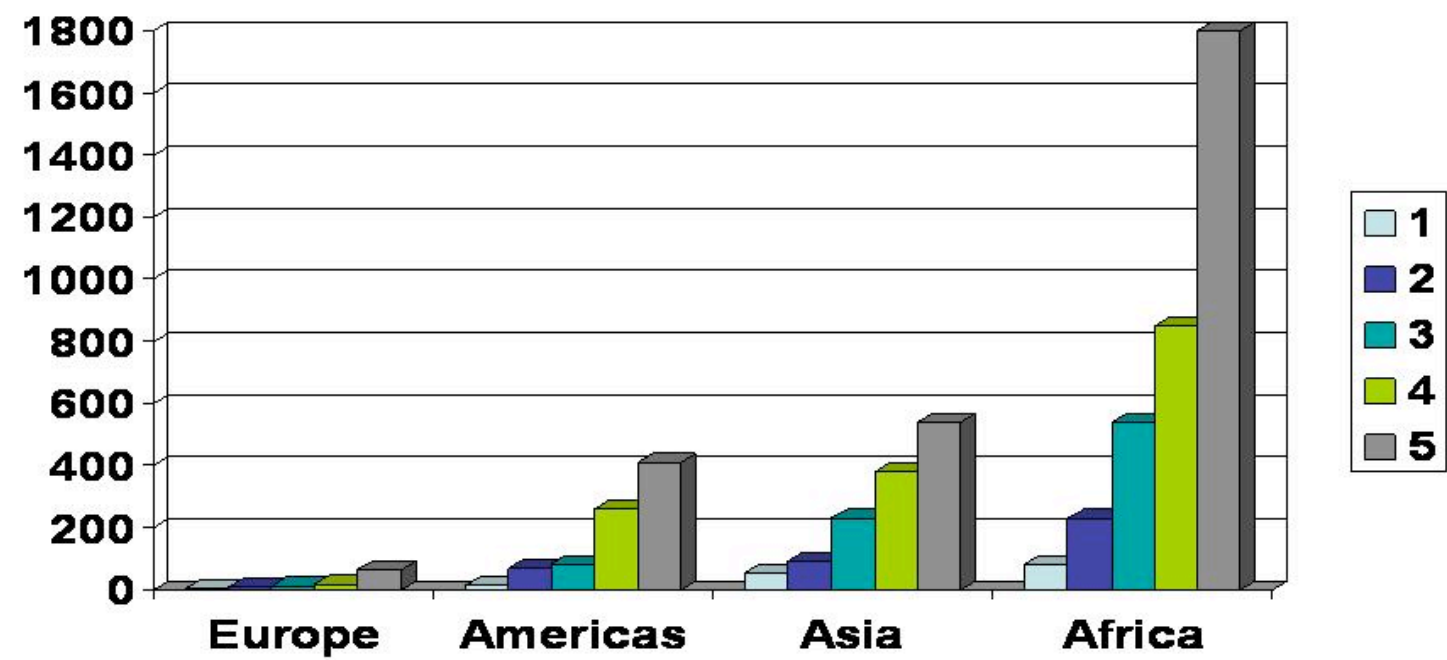
1. Finland (5)
USA (14)
2. Norway (10)
3. UK (11)
Argentina (70)
4. France (17)
Mexico (83)
5. Russia (65)

\begin{abstract}
China (56)
Sri Lanka (92)

Indonesia (230)

Bangladesh (380)

India (540)
\end{abstract}

\author{
Egypt (84) \\ South Africa (230) \\ Ghana (540) \\ Ethiopia (850) \\ Malawi (1800)
}

changing, with an increase in the number of indirect deaths. This may partly be due to better registration of indirect deaths and a shift in epidemiological trends (57). Among the direct causes, severe bleeding is in most areas the most frequent cause, accounting for approximately $25 \%$ of the total deaths, followed by infection (15\%), unsafe abortion (13\%), eclampsia $(12 \%)$, obstructed labour with or without rupture of the uterus $(8 \%)$ and other direct causes $(8 \%)$. The indirect causes that seem to account for an increasing proportion of the maternal deaths include anaemia, cardiovascular disease, malaria, tuberculosis, hepatitis and other infections. In some areas AIDS-related conditions are increasing as important indirect causes (8). The relative frequency of the different causes varies somewhat between areas. Some of us were involved in a population-based study in a low-endemicity malaria area in rural northern Tanzania, where $44 \%$ of maternal deaths were ascribed to cerebral malaria (7). A distribution as described above has, however, been observed in most areas with high maternal mortality ratios (e.g. in some sub-Saharan countries where in 1990 maternal mortality ratios have been estimated at more than 1,000 per 100,000 live births) (9).

\section{Severe bleeding}

Haemorrhage is the major cause of maternal deaths globally. In sub-Saharan African countries where data from more than one study are available, the proportion of maternal deaths due to postpartum haemorrhage ranges from $10 \%$ (five studies in Ethiopia) to $37 \%$ (three studies from Ivory Coast) (10). Postpartum haemorrhage can be rapidly fatal unless treatment is instituted without delay, and fatality rates are increased in areas where anaemia in pregnancy is widespread. The most frequent causes of postpartum bleeding are retained placenta and uterine atonia. Genital tract injuries occurring during delivery will exacerbate such bleedings, but do not frequently lead to death if other causes of bleeding are not present.

Antenatal haemorrhage is less common as a cause of maternal deaths, but the incidence is difficult to assess, especially in developing countries (10). The most common causes are placental abruption or placenta praevia. Whereas postpartum haemorrhage can be very rapidly fatal (estimated average interval from onset to death: 2 hours), antepartum haemorrhage is somewhat less acute (average interval from onset to death: 12 hours) (11).

\section{Infection}

Puerperal sepsis is still a common condition. According to reports of studies from sub-Saharan African countries where data from more than one study are available, it accounts for from $7.6 \%$ (data from two studies in Ghana) to $32.7 \%$ (data from three studies in Ivory Coast) of the total maternal deaths (12). Predisposing factors include caesarean section and other operative deliveries, frequent vaginal examinations, concurrent sexually transmitted infections, prolonged rupture of the membranes, retained products of conception and postpartum haemorrhage. 


\section{Unsafe abortion}

Unsafe abortion is defined by the World Health Organization (WHO) as a procedure for terminating an unwanted pregnancy either by a person lacking the necessary skills or in an environment lacking the minimal medical standards or both (13). Approximately one in eight maternal deaths is estimated to result from an unsafe abortion (14). A global estimate of the incidence of unsafe abortion suggests that approximately 20 million unsafe abortions take place every year, nearly $90 \%$ of which take place in the developing world. Between $10 \%$ and $50 \%$ of these will need medical attention. The typical complications of unsafe abortions are sepsis, haemorrhage, uterine perforation and lower genital tract injuries.

\section{Pre-eclampsia and eclampsia}

Pre-eclampsia is defined as development of gestational hypertension and significant proteinuria after 20 weeks of gestation, during labour or within 48 hours of delivery (15). Eclampsia comprises convulsions complicating pregnancy-induced hypertension antepartum, during labour or postpartum, in the absence of other neurological explanations for the seizures. Globally, it is estimated that $12 \%$ of all maternal deaths are related to these hypertensive disorders of pregnancy. In subSaharan Africa (in countries from which more than one report is available) this proportion is found to vary from 3\% in Uganda to 23\% in Mozambique (16).

\section{Obstructed labour}

Obstructed labour can be caused by cephalopelvic disproportion, deep transverse arrest, malpresentations and in rarer cases, foetal abnormalities, locked twins and pelvic tumours. In parts of the world where malnutrition, diseases and early marriage are common, obstructive labour is primarily due to cephalopelvic disproportion, and women of small stature and the very young are at highest risk. In sub-Saharan African countries where data from more than one study are available, the proportion of maternal deaths that is caused by obstructed labour and/or ruptured uterus vary from $7.0 \%$ in South Africa (two studies of deaths due to ruptured uterus) to $35.1 \%$ in Nigeria (18 studies of deaths due to obstructed labour and ruptured uterus) (17). The most serious complication from obstructed and prolonged labour is vesico-vaginal or rectovaginal fistulas. It has been estimated that between 1.5 and 2 million women in sub-Saharan Africa are living with such fistulas and between 50,000 and 100,000 new cases of fistulas develop each year (2) with grave physical and psychosocial suffering as a consequence.

\section{PreVENTION THROUGH IMPROVEMENTS OF THE HEALTH SYSTEM}

Reduction in the number of maternal deaths in relation to pregnancy and childbirth can be achieved through improvement of emergency care and reduction in delays of seeking care, through improvement of antenatal care, and through general health promotion and disease prevention activities. The causes of a maternal death have been classified into three phases of delay (18):

1) Phase 1, failure of a patient to seek appropriate medical care in time;

2) Phase 2, delay in reaching an adequate health care facility; and

3) Phase 3, delay in receiving adequate health care at the facility, including delay in referral.

Hoestermann et al. (19) found that $51 \%$ of the maternal deaths at the maternity unit of the main tertiary level hospital in Gambia were related to Phase 3 delays. Similarly, in Dar es Salaam, 72 of 93 maternal deaths in a referral hospital were related to sub-optimal medical care (20).

Phase 3 delay will influence delay in the two other phases. If adequate care is not available, patients will not bother to use time and money for reaching facilities that they know will not be able to help them with their problem. People generally know well whether a particular facility has competent, concerned staff and key services available (21). It is even unethical to encourage women to seek treatment for problems related to pregnancy if obstetric services do not exist or do not function. In Tanzania, a recent study found that the main barrier to use of quality obstetric care was not the mother's ignorance or ability to get to the facility. The actual quality of care and the critical services provided and the inequitable distribution of qualified staff between urban and rural areas were of greater importance (22-24).

Phase 2 delay is often due to lack of transport or low quality of roads, which is commonly a problem in many areas, especially in the rainy season. Development of a referral system and a system of transport and communication between peripheral areas and the facilities where emergency treatment can be given can significantly reduce maternal mortality (25). Phase 1 delay can be reduced through community education with information, targeted to women as well as to men, about the importance of pregnancy care and the necessity of seeking care in time in cases of prolonged labour.

Historic data support the contention that improvement in health care is more important than general socioeconomic development for the fall in maternal mortality. Thus, data from countries like Sri Lanka, Cuba and China show that health care interventions including improvement of access to emergency obstetric care, were followed by a fall in maternal mortality even without major socioeconomic changes (9). Further, in a group of women in the United States that for religious reasons rejected all medical care during pregnancy and childbirth, a maternal mortality ratio of 870 per 100,000 live births was observed (26). Thus, lack of good medical care is the main cause of persisting high maternal mortality figures in many countries. 


\section{SPECIFIC PREVENTIVE MEASURES}

\section{Haemorrhage}

Because of the urgency of a postpartum haemorrhage, maternal deaths from such bleeding are difficult to prevent unless the health system is well organised. For this reason, such bleeding tends to remain the cause of death that is slowest to respond to maternal health care interventions (10).

Most women with postpartum haemorrhage in developing countries will not reach adequate health care facilities in time. Skills in the management of retained placenta and correct use of medications should therefore be extended to personnel who first come into contact with the pregnant women in cases of such emergencies. Simple skills include techniques of uterine massage, elevation of the limbs, and use of oxytocic drugs. These skills should be mastered by all local health workers in the periphery and could even be taught to traditional birth attendants since, in emergency situations, a large proportion of the women in developing countries still turn to them for help (8). However, in order to be successful, such training requires close and sustained follow-up of skilled personnel. Without such back-up, training of traditional birth attendants has proved to be unsuccessful at reducing maternal mortality (27).

There are also great potentials for improvements on the level of the referral hospital. In a study in Dar es Salaam in Tanzania it was found that a large proportion of maternal deaths were linked to lack of possibilities for blood transfusion and lack of drugs, even in the tertiary referral centre (20). In a hospital based study where a large reduction in maternal mortality was achieved (28), establishment of an infusion production unit and a blood donor recruitment system with early provision of blood for transfusion when required, were among the measures introduced.

\section{Infection and sepsis}

The incidence of infection can be reduced through improved cleanliness during delivery, whether the delivery occurs at home or within a health care facility. The importance of clean delivery practice was shown in the middle of the 19th century by Semmelweis in Austria. He understood that puerperal sepsis very often was an iatrogenic infection and that hygienic measures were essential for prevention. By appropriate intervention he achieved a reduction in maternal mortality from $5 \%$ to $1.3 \%$ of deliveries (29).

With the introduction of antibiotics, puerperal sepsis declined further in industrialized countries. Early detection of postpartum infections and appropriate use of antibiotics is now a sine qua non for prevention of deaths due to infection. Thus, it has been shown that prophylactic use of antibiotics at operative deliveries will contribute to reduce the incidence of infection (30).
Sepsis is usually the first cause of death to decline when appropriate maternity care becomes available, especially if the maternal mortality was originally high (12). In many studies lack of drugs has been identified as an important cause of inadequate treatment $(19,20)$. In an intervention study by Mbaruku and Bergstrøm (28) in Tanzania, a plan for supply of essential drugs, including broad spectrum antibiotics, establishment of microbiologic culture facilities and proper procedures for sterilization and disinfection were among the measures that were associated with a decrease in maternal mortality.

\section{Unsafe abortion}

The legal status of abortion is a key determinant of access to safe abortion. Women will normally obtain abortion also in countries where abortions are against the law, the more affluent women obtaining relatively safe procedures, whereas the poor women usually suffer the severe consequences, adolescents being particularly vulnerable. In Romania, after legalisation of abortion in 1989, maternal deaths related to abortions fell from around 130 per 100,000 live births in the years before to around 60 per 100,000 live births in the year after abortion was legalized (14). Thus, the number of unsafe abortions with serious complications could be substantially reduced through universal legal access to safe abortion facilities, availability of necessary drugs and competence in the treatment of complications. However, even where abortion is legally available, unsafe abortion continues to occur, since safe services may be inaccessible due to distance, costs, lack of confidentiality or poor quality of care (31).

In countries where legal termination of pregnancy is not available, much can still be done to prevent abortion-related mortality by high quality treatment of complications. This may include surgical intervention and prophylactic therapy with antibiotics in cases of early incomplete abortion, and emergency antibiotic therapy, blood transfusions and surgical interventions for women with serious complications coming for treatment (13).

\section{Eclampsia}

Adequate antenatal monitoring and referral when signs and symptoms of pre-eclampsia occur could result in a substantial reduction in mortality due to eclampsia (4). However, in most low-income countries, women will not be able to follow the advice given, even if significant proteinuria and hypertension are diagnosed. Further, even in situations where pregnant women come for antenatal care in the formal health system, urine is often not tested. Thus, in a study in Tanzania it was found that $98.2 \%$ of the women attended antenatal care, but less than half of them ever had their urine tested (32).

On this background, the most realistic way of reducing mortality due to eclampsia may still be to ensure 
that women get necessary treatment if eclampsia develops. In Sweden, improvement in treatment of eclampsia resulted in a decrease in the case fatality rate from $14 \%$ in $1950-55$ to $3 \%$ in $1971-80$ (33). Thus, it is important to ensure availability of the drug of choice (magnesium sulphate) and to train midwives and other health personnel in the primary health care system in appropriate use of this drug.

\section{Obstructed labour}

Mortality from obstructed labour could be greatly reduced by early detection and referral to centres with facilities for operative delivery. Emergency caesarean section can be taught to midwives, nurses and paramedical personnel who, after appropriate training, can perform this operation as safely as medical doctors (34). An additional measure can be to advise women at particular high risk (e.g. those with a previous history of prolonged and difficult delivery and young primiparous women with low stature) to travel to a maternity waiting home or relatives near a health facility with possibility for performing caesarean section. Further, community education of the dangers of not seeking care in time in cases of prolonged labour constitutes an important component of an intervention programme. This information should be targeted also to the men who in most cases are the decision-makers in relation to the question of seeking care in an emergency situation. Improved management of these cases after reaching the hospital is essential, also for this cause of maternal death. Thus, Mbaruku and Bergstrøm (28) managed through a hospital based intervention programme in Tanzania to reduce the annual number of maternal deaths due to uterine rupture from 7-10 before to 1-2 after the intervention programme was introduced.

\section{ROLE OF ANTENATAL CARE}

One of the main pillars of the strategy for reducing maternal mortality has been the promotion of antenatal care, and it has been estimated that around $65 \%$ of pregnant women in developing countries have access to such care (9). Antenatal clinics serve as an important arena for health education, vaccinations and treatment of illnesses during pregnancy. Further, there are studies showing that high level of antenatal care is related to use of trained assistance at delivery (35), indicating that such care contributes to lowering the barriers between pregnant women and the formal health system. Proper antenatal care is necessary to detect and treat indirect causes of maternal mortality and can also, if properly conducted, contribute to the prevention of direct causes. In several low-income countries, testing and treating pregnant women for HIV and malaria is now being planned to become an integrated part of the antenatal services. However, little is known of the general quality of the care given and the importance of this care for detecting and preventing condi- tions that contribute to maternal deaths (9), and it is important to note that the majority of the maternal deaths occur among women that are not identified as being at high risk (36).

Furthermore, very often the equipment for detecting women at risk and drugs for giving the necessary treatment are lacking. In a population-based study in Northern Tanzania in 1998, Eseko (32) found that almost all women attended antenatal clinics during pregnancy, but less than half of them had ever had a blood test for haemoglobin measurement or their urine tested, and pelvic assessment was done for only $13 \%$. Even in situations where high risk women are identified and the correct advice given at the antenatal examination, appropriate actions are often not taken. The reasons for not following the advice are diverse; the costs and inconvenience involved, other priorities held by the decision-makers in the household (e.g. husband, mother-in-law) or lack of trust in the formal health system.

There is scarce evidence for an effect of antenatal care on pregnancy outcome in areas where adequate obstetric care is lacking. In Tanzania, Møller et al. (37) found no relationship between the number of antenatal visits and the pregnancy outcome. Further, Jahn et al. (38) showed that despite pursuing the risk approach and very good coverage, antenatal care had only limited effect on extending obstetric care to high-risk mothers. It has been shown that an antenatal programme with fewer and more objectively oriented visits can be introduced without adverse effects on the main intermediate outcome pregnancy variables (39). In sum, these studies suggest that in developing countries priority should be given to obstetric care, and that the content of antenatal care in these countries should be critically reviewed. A new model of antenatal care has been designed and tested under the auspices of WHO, targeting examinations and interventions that have been scientifically shown to be effective. With fewer visits for those at lowest risk, more time to communicate with the pregnant women, clear rules for referral and in some settings at less cost, the new model may help to improve antenatal care services in poor countries (40).

\section{LOST OPPORTUNITIES AND NEW INITIATIVES FOR REDUCING MATERNAL MORTALITY}

The persistent high maternal mortality was for many years a neglected tragedy (3), but has during the last 20 years been given increased attention. The first major international meeting to focus on this problem was held by WHO in 1985, and in 1987 the first international Safe Motherhood conference was held in Nairobi. In the years 1987 to 1994 at least 18 international or regional meetings were held in order to raise awareness among policymakers (41). In 1994, the lack of progress led to the following statement by Bergström: "While a dramatic improvement of maternal mortality 
figures would have been within reach at a highly bearable cost we may have to witness that maternal mortality figures continue to increase. There is reason for concern in the era of safe motherhood rhetorics" (42).

In 1998 "Safe Motherhood" was the slogan for the World Health Day. However, seven years later the progress is still slow, and on the World Health Day, April $7^{\text {th }}, 2005$, in New Delhi, the topic was again the same. The World Health Report 2005, entitled: "Make every mother and child count" (1) was then launched, and the WHO Director-General Dr. Lee Jong-wook stated: "More than six million children could be saved if they have simple health care and thousands of women could be saved if they had access to skilled care. The millennium goals for health are attainable; our message today is one of hope". To this end many high level stakeholders endorsed a "Delhi declaration on maternal, newborn and child health" (43). The declaration describes several concrete actions that are urgently needed for improvement of maternal and child care to take place within 2007. The declaration proposes development of national targets and plans of actions and the mobilizing of resources for necessary coverage of care, to meet the shortages of skilled personnel and for developing systems for monitoring progress.

It is, however, sad to see that international initiatives have been slow to produce concrete results in reducing the maternal mortality, especially in lowincome countries. One reason may be that the Safe Motherhood Initiative when it was launched in 1987 (44) was too broad and multifaceted (45). Improvements in women's status, educational opportunities and access to family planning, have not yet had the expected outcome in terms of reduction in maternal mortality. The Initiative might even have diverted attention from the main areas which in several settings have proved to be effective: The organisation of effective programmes of obstetric care through collaboration between the policy-makers and the medical community.

\section{IMPORTANCE OF SKILLED OBSTETRIC CARE}

Since the key to reduction in maternal mortality is improvement of medical care, medical doctors, and in particular obstetricians, have an important role to play. Obstetricians have the necessary knowledge and skills, but they are few, in particular in countries where maternal mortality is high. Therefore, their main responsibility will be to transfer the necessary knowledge and skills to other actors in the health care system and to help organise the system in a way that secures pregnant women access to skilled personnel at facilities with the necessary equipment and drugs. The running of the programme should be independent of their presence.

It is widely recognized that midwives or other midlevel health workers must constitute the core of any maternity care programme. When properly trained, they can perform caesarean sections, tubal ligations and legal abortions with good results $(34,42,46)$. As pointed out by De Brouwere et al. (46), one important reason for the first phase of the fall in maternal mortality in the industrialized countries was making professional midwifery care available to a large part of the population. In countries such as Sweden, and later in the Netherlands, Denmark and Norway, this constituted an important part of the strategy. Already in the early part of the last century, these countries obtained reductions in maternal mortality corresponding to $25 \%$ of the rates in the poorest countries today (46).

An important precondition for success is that a programme is tailored to the local situation, since there are great variations between areas in quality of services, availability of equipment, drugs and trained personnel and use of traditional birth attendants. Therefore, there is no standard formula for whom should be taught what in relation to the provision of adequate care to pregnant women. The actions needed to achieve adequate facilities and appropriate training activities will thus vary from place to place, and the actions taken should be assessed for each particular situation (21). There are examples of successes of different types of programmes. Reduction in maternal mortality ratios may be achieved through programmes involving training of village health workers and traditional birth attendants (47), through training of obstetric nurses to perform caesarean sections and symphysiotomies (48), through training of doctors and midwives (47) and through a multipurpose hospital based programme which included training of all cadres of health personnel (28).

The obstetrician, who knows what are the most important components of a good programme, should be in the best position to assess the deficiencies in the services and to, in collaboration with health personnel on all levels, develop programmes for improvement. The study of Mbaruku and Bergström (28) is a good example of how obstetricians can take a lead to improve the services. After an assessment of the situation, a multipurpose programme for intervention was launched; this resulted in a dramatic fall in maternal deaths. Among the measures introduced the authors concluded that the most important preconditions for the fall in maternal mortality in this hospital setting seemed to be

- Improvement in availability of necessary drugs and intravenous infusions

- Improvement of equipment for sterilization and surgical operations

- Improved availability of essential staff

- Improvement in skills and responsibility of the workers at all levels

When a programme like this is introduced, the obstetrician is the key person for securing its sustainability through development of systems for continuing training and supervision. The additional costs necessary to 
make already existing facilities function adequately are small in relation to the cost already spent in these facilities on personnel and measures that often produce little health gain. In this context it is important to develop systems that secure that the necessary personnel are available when on duty and to foster increased responsibility and awareness of those involved in care at all levels.

Education of the public is the next important step, focusing more on the men, with emphasis on the importance of reaching the appropriate care level in time for pregnancy related conditions in order to reduce the Phase I-delays and Phase II-delays described above. However, it is of little use to encourage women to seek care in the formal health system, before it is secured that the system can provide the care that is needed.

\section{CONCLUSION}

The persistence of high rates of maternal mortality in a world where the means to solve this problem have long been available, is a moral problem. The medical community as a whole and the obstetricians in particular, have an important role to play in creating awareness of the problem internationally and in individual countries. The tools to substantially reduce the problem of maternal mortality are known. However, although necessary interventions are very cost-effective, a substantial increase in the resources for reproductive health care services is needed, and the human resource crises in the health system must be urgently addressed (1). The international community should give higher priority to the problem of maternal mortality than to other programmes where preventive measures are more complicated and less cost-effective. Several authors have pointed to the need for concerted actions from decision-makers at different levels, funding agencies and the medical community $(45,50)$. In 1999, when addressing the problem of maternal mortality as the Director-General of WHO, Dr. Gro Harlem Brundtland, stated: "There is a human rights imperative involved ... There are no more excuses for failing to act" (51). However, unless all stakeholders globally and within individual countries will demonstrate a real commitment to translate policy statements into actions, there is little hope that the goal of reducing maternal mortality by three quarters by 2015 will be met.

\section{EPILOGUE - THE ROLE OF EPIDEMIOLOGIC RESEARCH FOR REDUCING MATERNAL MORTALITY}

Since all major causes and avenues for prevention of maternal deaths have been well described, one could be lead to conclude that we do not need more research on these issues. First and foremost we need to implement what we already know. We need to intensify advocacy for convincing governments, policy makers and important stakeholders on international, national and sub-national level to made the necessary decisions and provide the resources needed to solve this problem. However, 50 years of advocacy have had a very low impact. Therefore, in addition to intensified advocacy, we need to study how we, in different lowresource settings, can use the available manpower and other resources more efficiently to achieve a reduction in maternal mortality. In this context, epidemiologists have a very important role to play.

Methodologically sound intervention studies are urgently needed. Epidemiologists should join forces with obstetricians to study how to influence the health systems factors causing the persisting high maternal mortality. Within the field of perinatal epidemiology the disparity in public health importance of research conducted in the rich versus the poor world is glaring. Time is overdue for perinatal epidemiologists to turn their attention to the areas of the world where the maternal and perinatal problems are present.

A recent study in the New England Journal of Medicine (52) can serve as an example of studies that can have direct consequences for prevention. Through a cluster-randomized design, an intervention of training and issuing disposable delivery kits to traditional birth attendants in rural Pakistan resulted in a significant reduction in maternal mortality and perinatal deaths. We need similar studies in different low-resource setting on how to introduce in the health systems interventions that we know are effective if applied appropriately. There is a greater need for randomized controlled trials for estimating the effect of different health care systems interventions aimed at reducing maternal mortality and other health problems in low resource settings, than for mounting such studies for investigating effects of new vaccines and drugs. The focus of the health research community and resources for research should thus be redirected accordingly.

\section{REFERENCES}

1. WHO. World health report 2005. Make every mother and child count. Geneva: WHO, 2005.

2. Waldijk K. Surgeons show success in early fistula repairs. Safe Motherhood Newsletter, Issue 14, March-June 1994.

3. Rosenfield A, Maine D. Maternal mortality - a neglected tragedy: Where is the M in MCH? Lancet 1985; 2: 83-5.

4. WHO. The Mother-Baby Package: Implementing Safe Motherhood in Countries. Geneva: WHO, 1994. 
5. de Swiet M. Maternal mortality: confidential enquiries into maternal deaths in the United Kingdom. Am $J$ Obstet Gynecol 2000; 182: 760-6.

6 Mayor S. Poorest women 20 times more likely to die in childbirth. Br Med J 2001; 323: 1324.

7. Olsen BE, Hinderaker SG, Bergsjø P, Lie RT, Olsen OHE, Gasheka P, Kvåle G. Causes and characteristics of maternal deaths in rural northern Tanzania. Acta Obstet Gynecol Scand 2002; 81: 1101-9.

8. MacLeod J, Rhode R. Retrospective follow-up of maternal deaths and their associated risk factors in a rural district of Tanzania. Trop Med Int Health 1998; 3: 130-7.

9. AbouZahr C. Maternal mortality overview. In: Murray CJL, Lopez AD, eds.. Health Dimensions of Sex and Reproduction. Global Burden of Disease and Injury Series Volume III. WHO, Harvard School of Public Health and the World Bank, Harvard University Press, 1998: 111-64.

10. AbouZahr C. Antepartum and postpartum hemorrhage. In: Murray CJL, Lopez A, eds. Health Dimensions of Sex and Reproduction. Global Burden of Disease and Injury Series Volume III. WHO, Harvard School of Public Health and the World Bank, Harvard University Press, 1998: 165-90.

11. Maine D. Safe Motherhood Programs: Options and Issues. Center for Population and Family Health, Faculty of Medicine, Columbia University, New York, 1992.

12. AbouZahr C, Åhman E, Guidotti R. Puerperal sepsis and other puerperal infections. In: Murray CJL, Lopez AD, eds. Health Dimensions of Sex and Reproduction. Global Burden of Disease and Injury Series Volume III. WHO, Harvard School of Public Health and the World Bank, Harvard University Press, 1998: 191-218.

13. WHO. The prevention and management of unsafe abortion. Report of a Technical Working Group. Geneva, 12-15 April 1992, WHO/MSM/92.5, 1992.

14. AbouZahr C, Åhman E. Unsafe abortion and ectopic pregnancy. In: Murray CJL, Lopez AD, eds. Health Dimensions of Sex and Reproduction. Global Burden of Disease and Injury Series Volume III. WHO, Harvard School of Public Health and the World Bank, Harvard University Press, 1998: 267-96.

15. WHO. The hypertensive disorders of pregnancy: Report of a WHO study group. Technical report series No. 758, Geneva, 1987.

16. AbouZahr C, Guidotti R. Hypertensive disorders of pregnancy. In: Murray CJL, Lopez AD, eds. Health Dimensions of Sex and Reproduction. Global Burden of Disease and Injury Series Volume III. WHO, Harvard School of Public Health and the World Bank, Harvard University Press, 1998: 219-41.

17. AbouZahr C. Prolonged and obstructed labour. In: Murray CJL, Lopez AD, eds. Health Dimensions of Sex and Reproduction. Global Burden of Disease and Injury Series Volume III. WHO, Harvard School of Public Health and the World Bank, Harvard University Press, 1998: 243-66.

18. Thaddeus S, Maine D. Too far to walk: maternal mortality in context. Soc Sci Med 1994; 38: 1091-110.

19. Hoestermann CFL, Ogbaselassie G, Wacker J, Bastert G. Maternal mortality in the main referral hospital in The Gambia, West Africa. Trop Med Int Health 1996; 1: 710-7.

20. Urassa E, Massawe S, Lindmark G, Nystrom L. Operational factors affecting maternal mortality in Tanzania. Health Policy Plan 1997; 12: 50-7.

21. Maine D. Lessons for program design from the PMM projects. Int J Gynecol Obstet 1997; 59 (Suppl 2): S259-S265.

22. Olsen ØE, Ndeki S, Norheim OF. Complicated deliveries, critical care and quality in emergency obstetric care in Northern Tanzania. Int J Gynecol Obstet 2004; 87: 98-108.

23. Olsen ØE, Ndeki S, Norheim OF. Availability, distribution and use of emergency obstetric care in northern Tanzania. Health Policy Plan 2005; 20: 167-75.

24. Olsen ØE, Ndeki S, Norheim OF. Human resources for emergency obstetric care in northern Tanzania: distribution of quantity or quality? Hum Resour Health 2005; 29: 3-5.

25. WHO. Essential elements of obstetric care at first referral level. Geneva: WHO, 1991.

26. Kaunitz AM, Spence C, Danielson TS, Rochat RW, Grimes DA. Perinatal and maternal mortality in a religious group avoiding obstetric care. Am J Obstet Gynecol 1984; 150: 826-31.

27. Family Care International and Safe Motherhood Interagency Group. Ensure skilled attendance at delivery. Safe Motherhood Fact Sheet, 1998.

28. Mbaruku G, Bergström S. Reducing maternal mortality in Kigoma, Tanzania. Health Policy Plan 1995; 10: 71-8.

29. Semmelweis IP. Die Aetiologie, der Begriff und die Prophylaxis des Kindbettfiebers. Pest-Wien-Leipzig, 1861.

30. Charles D, Larsen B. Puerperal sepsis. In: Turnball A, Chamberlain G, eds. Obstetrics. Churchill Livingstone, 1989.

31. Machungo F, Zanconato G, Bergström S. Reproductive characteristics and post-abortion health consequences in women undergoing illegal and legal abortion in Maputo. Soc Sci Med 1997; 45: 1607-13.

32. Eseko N. Analysis of maternal and perinatal care systems in Tanzania and assessment of the actual situation in Arusha region. Master Thesis, Centre for International Health, University of Bergen, Norway, 1998. 
33. Høgberg U. Maternal mortality in Sweden. Umeå: Umeå University, 1985.

34. White SM, Thorpe RG, Maine D. Emergency obstetric surgery performed by nurses in Zaire. Lancet 1987; 2: 612-3.

35. Bloom SS, Lippeveld T, Wypij D. Does antenatal care make a difference to safe delivery? A study in urban Uttar Pradesh, India. Health Policy Plan 1999; 14: 38-48.

36. Winikoff B, Sullivan M. Assessing the role of family planning in reducing maternal mortality. Stud Fam Plan 1987; 18: 128-43.

37. Møller B, Lushino O, Meirik O, Gebre-Medhin M, Lindmark G. A study of antenatal care at village level in rural Tanzania. Int J Gynaecol Obstet 1989; 30: 123-31.

38. Jahn A, Kowalewaski M, Kimatta SS. Obstetric care in southern Tanzania: does it reach those in need? Trop Med Int Health 1998; 3: 926-32.

39. Munjanja SP, Lindmark G, Nystrom L. Randomized controlled trial of a reduced-visits programme of antenatal care in Harare, Zimbabwe. Lancet 1996; 348: 364-9.

40. Villar J, Ba'aqueel H, Piaggio G, Lumbiganon P, Belizán JM, Farnot U, et al, for the WHO Antenatal Care Trial Research Group. WHO antenatal care randomised controlled trial for the evaluation of a new model of routine antenatal care. Lancet 2001; 357: 1551-64.

41. Rosenfield A. The history of the safe mootherhood initiative. Int J Gynecol Obstet 1997; 59 (Suppl 2): S7-S9.

42. Bergström S. Maternal health. A priority in reproductive health. In: Lankinen et al., eds. Health and disease in developing countries. London: Macmillan Press, 1994: 305-15.

43. Delhi declaration on maternal, newborn and child health. New Delhi 9. April 2005. www.who.int/entity/world-health-day/2005/activities/delhi_declaration.pdf.

44. Mahler H. The Safe Motherhood Initiative: a call to action. Lancet 1987; i: 668-70.

45. Weil O, Fernandez, H. Is safe motherhood an orphan initiative. Lancet 1999; 354: 940-3.

46. De Brouwere V, Tonglet R, Van Lerberghe W. Strategies for reducing maternal mortality in developing countries: what can we learn from the history of the industrialized West? Trop Med Int Health 1998; 3: 771-82.

47. Greenwood AM, Bradley AK, Byass P, Greenwood BM, Snow RW, Bennett S, Hatib-N'Jie AB. Evaluation of a primary health care programme in The Gambia. I. The impact of trained traditional birth attendants on the outcome of pregnancy. J Trop Med Hyg 1990; 93: 58-66.

48. Duale S, Herman C, Pelrick T, Lampe P. A follow-up study of pregnant women with symphysiotomy versus cesarean section in Zaire. Washington, DC: The International Center for Research on Women, 1990.

49. Oyesola R, Shehu D, Ikeh AT, Maru I. Improving emergency obstetric care at a state referral hospital, Kebbi State, Nigeria. Int J Gynecol Obstet 1997; 59 (Suppl 2): S75-S81.

50. Liljestrand J. Reducing perinatal and maternal mortality in the world: the major challenges. Br J Obstet Gynaec 1999; 106: 877-80.

51. Harlem Brundtland G. Address to the General Assembly Special Session on ICPD+5, New York, 30 June - 2 July, 1999.

52. Jokhio AH, Winter HR, Cheng KK. An intervention involving traditional birth attendants and perinatal and maternal mortality in Pakistan. N Engl J Med 2005; 352: 2091-9. 